\title{
Magnetic resonance findings in subacute combined degeneration
}

\author{
Achados na RM em degeneração combinada subaguda \\ Christiane Maria França Coimbra ${ }^{1}$, Samara Oliveira Dias ${ }^{1}$ Neysa Regattieri', Flávio Luz Garcia Pires ${ }^{1}$
}

A 47-year-old man presented with paresthesia of the arms, disorientation and ataxia. Past medical history included alcoholism, and cholecystectomy one week prior (nitrous oxide was administrated during anesthesia). Neuroimaging revealed bilateral symmetric high signal within the dorsal columns of the cervical cord, suggesting the diagnosis of subacute combined degeneration. On cross-section images, this appearance has been described as the "inverted V sign" (Figure A, B). The laboratory test showed a low serum vitamin B12 level, confirming the diagnosis. Once the deficiency was corrected, the patient improved clinically and the spinal cord signal changes had subsided by the three-month follow-up (Figure C, D) $)^{1,2,3}$.
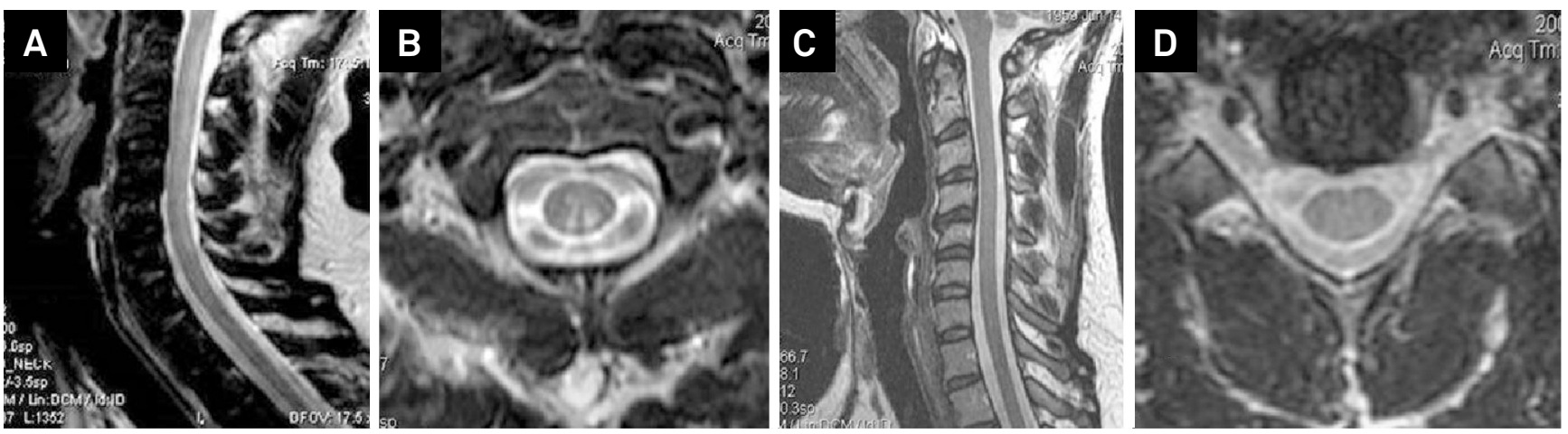

Figure. Neuroimaging findings in subacute combined degeneration. Sagittal and axial MR spinal images on T2-weighted sequences demonstrate abnormal high signal within the dorsal columns of the cervical cord (A, B), and the complete resolution of signal abnormalities at a three-month follow-up (C, D).

1. $\quad$ Sun HY, Lee JW, Park KS, Wi JY, Kang HS. Spine MR imaging features of subacute combined degeneration patients. Eur Spine J. 2014;23(5):1052-8. https://doi.org/10.1007/s00586-014-3191-4

2. Hathout L, El-Saden S. Nitrous oxide-induced B12 deficiency myelopathy: perspectives on the clinical biochemistry of vitamin B12.J Neurol Sci. 2011;301(1-2):1-8. https://doi.org/10.1016/j.jns.2010.10.033
3. Gupta PK, Gupta RK, Garg RK, Rai Y, Roy B, Pandey CM et al. DTI correlates of cognition in conventional MRI of normal-appearing brain in patients with clinical features of subacute combined degeneration and biochemically proven vitamin B(12) deficiency. AJNR Am J Neuroradiol. 2014;35(5):872-77.

https://doi.org/10.3174/ajnr.A3785

\footnotetext{
${ }^{1}$ Hospital Universitário de Brasília, Unidade de Diagnóstico por Imagem, Brasília DF, Brasil.

Correspondence: Samara Oliveira Dias; Hospital Universitário de Brasília, Radiologia e Diagnóstico por Imagem; SGAN 605, Av. L2 Norte; 70840-90 Brasília DF, Brasil; E-mail:samaradias1@gmail.com
}

Conflict of interest: There is no conflict of interest to declare.

Received 10 October 2016; Received in final form 01 March 2017; Accepted 14 March 2017. 